\title{
Evaluation of antibiotic prescriptions for sepsis in the Neonatal Intensive Care Unit in a Tertiary Hospital in North Sumatera, Indonesia
}

\author{
AYODHIA PITALOKA PASARIBU 1, 2, A, D, E-G, BEBY SYOFIANI 1, 2, A, F, FAHMI FAHMI3, c, D, \\ ORCID ID: 0000-0002-3830-8073 $\quad$ ORCID ID: 0000-0002-7858-2245 ORCID ID: 0000-0002-6760-4824 \\ FAUZAN AZIMA DALIMUNTHE ${ }^{4, ~ B}$, MAULANA JAMIL NASUTION ${ }^{4, ~ B}$, SYAHRIL PASARIBU $^{1, \text { A, E }}$ \\ $\begin{array}{lll}\text { ORCID ID: 0000-0002-7533-465X } & \text { ORCID ID: 0000-0002-1708-5990 ORCID ID: 0000-0001-6640-687X }\end{array}$ \\ ${ }^{1}$ Department of Child Health, Medical Faculty, Universitas Sumatera Utara, Medan, Indonesia \\ ${ }^{2}$ Adam Malik General Hospital, Medan, Indonesia \\ ${ }^{3}$ Department of Electrical Engineering, Faculty of Engineering, Universitas Sumatera Utara, Medan, Indonesia \\ ${ }^{4}$ Medical Faculty, Universitas Sumatera Utara, Medan, Indonesia
}

A - Study Design, B - Data Collection, C - Statistical Analysis, D - Data Interpretation, E - Manuscript Preparation, F - Literature Search, G - Funds Collection

Summary Background. Neonatal sepsis is a leading cause of morbidity and mortality worldwide. The evaluation of antibiotic prescription in neonatal intensive care units (NICUs) is important for reducing inappropriate antibiotic use and minimizing the development of antibiotic resistance. Antimicrobial stewardship programs potentially promote a prudent use of antibiotics; however, the approach in NICUs is not yet optimal.

Objectives. The aim of our study was to evaluate antibiotic prescriptions for neonatal sepsis in a tertiary hospital in North Sumatera, Indonesia.

Material and methods. In our retrospective study, we collected data from medical records and enrolled 324 neonatal sepsis patients who received one or more antibiotics.

Results. Gentamycin and cefotaxime were the two most common antibiotics prescribed in the NICU $(72.22 \%$ and $71.60 \%$, respectively). However, high levels of resistance to gentamycin and cefotaxime were found among common pathogens circulating in the NICU ( $55.56 \%$ and $82.81 \%$, respectively). Only $40.33 \%$ of the antibiotic prescriptions were appropriate: approximately $15.11 \%$ of the patients had received antibiotics with incorrect indications and $16.16 \%$ of the antibiotics had been administered without sufficient duration. Conclusions. The appropriate use of antibiotic prescriptions in the NICU was low, which may lead to high mortality in neonatal sepsis patients. Continued evaluation of antibiotic usage by implementing antimicrobial stewardship programs in the NICU is important. Key words: anti-bacterial agents, neonatal sepsis, prescriptions.

Pasaribu AP, Syofiani B, Fahmi F, Dalimunthe FA, Nasution MJ, Pasaribu S.Evaluation of antibiotic prescriptions for sepsis in the Neonatal Intensive Care Unit in a Tertiary Hospital in North Sumatera, Indonesia. Fam Med Prim Care Rev 2021; 23(3): 337-340, doi: https://doi. org/10.5114/fmpcr.2021.108200.

\section{Background}

Neonatal sepsis is one of the major causes of infant mortality, accounting for $13 \%$ of neonatal deaths worldwide, especially in developing countries [1]. Antibiotics are the most commonly used medications in newborn wards and neonatal intensive care units (NICUs) [2]. Neonatal sepsis has nonspecific manifestations and results in serious complications. Therefore, clinicians often administer antibiotics to infants at high risk of sepsis during hospitalization, despite only $5 \%$ of culture results returning positive $[2,3]$. Approximately $60 \%$ of antibiotics are administered for more than 72 hours even in the presence of a negative blood culture, and a prolonged use of antibiotics is known to increase the risk of late-onset sepsis, necrotizing enterocolitis, and even death $[3,4]$. Some studies have found that the overuse of antibiotics in NICUs is common in developing countries, where $35 \%$ of neonates received at least one inappropriate antibiotic during their stay $[5,6]$. Inappropriate use of antibiotics is associated with the development and spread of resistant pathogens $[7,8]$. Multidrug-resistant strains causing sepsis are associated with increased mortality, excessive cost, and therapeutic challenges [9]. A prudent use of antibiotics in the NICU is very important for the protection of this vulnerable population [10].

\section{Objectives}

The aim of this study was to evaluate antibiotic prescriptions for neonatal sepsis in a tertiary hospital in North Sumatera, Indonesia. The assessment of antibiotics prescribed in the NICU as part of antimicrobial stewardship programs is necessary to evaluate the appropriate choice of antibiotics.

\section{Material and methods}

The Adam Malik Hospital is a tertiary hospital in North Sumatera, Indonesia. It has a special ward for babies and an NICU with 30 beds. Each month, 30-60 babies are treated in this ward. The majority of the diagnoses are for sepsis, and the patients are prescribed various antibiotics. We conducted a retrospective study based on medical records. All neonates who were hospitalized in 2018 and diagnosed with sepsis - either confirmed by blood culture results or clinically suspected 
- and who received one or more antibiotics were included in this study. Incomplete data or medical records that could not be found were grounds for exclusion. Sensitivity to various antibiotics was also found in the culture results. Empirical antibiotics were considered inappropriate if the pathogens were resistant to the antibiotic used. Demographic variables such as sex, type of sepsis, and pathogens found were analyzed, as well as variables associated with the use of antibiotics such as type of antibiotics, dosage, duration, and reason for switching or stopping.

We assessed the quality of antibiotic use according to the method of Gyssens et al. to evaluate each parameter of importance associated with antibiotic use $[11,12]$. Antibiotic usage was evaluated based on the Gyssens flowchart as follows: appropriate use (0), incomplete data for evaluation (VI), no antibiotic indication (V), improper choice of antibiotic (IVA-IVD), inadequate duration (IIIA-IIIB), and improper dosage interval (IIA-IIC, I).

Prescriptions were considered therapeutic if the medical record contained information that the antibiotic was prescribed for treatment or that any clinical sign of infection occurred. Antibiotics were considered prophylactic if the medical record stated that the antibiotic was prescribed for prevention. Three investigators, one Pediatric Infectious Diseases Consultant and two clinical pharmacologists, independently reviewed the medical records. The assessment of each reviewer was summarized in a combined evaluation when at least two reviewers evaluated the prescription as appropriate, not indicated, or inappropriate.

All statistical procedures were performed using STATA version 15.1 (Stata Corporation, College Station, Texas, USA). Descriptive data are expressed as the mean and percentage (\%).

The Universitas Sumatera Utara Institutional Review Board (IRB) approved the protocol for this study (no. 239/TGL/KEPK FK USU-RSUP HAM/2019).

\section{Results}

A total of 351 neonates were admitted to the NICU in 2018, and 324 of them were diagnosed with sepsis and administered one or more antibiotics. Approximately half (58.6\%) of them were female and $83.65 \%$ had been diagnosed with clinical sepsis. Detailed characteristics of the patients are shown in Table 1.

\begin{tabular}{|c|c|c|}
\hline Characteristics & $\begin{array}{l}\text { Number of pa- } \\
\text { tients }(n=324)\end{array}$ & $\begin{array}{l}\text { Percent } \\
\text { of patients }\end{array}$ \\
\hline $\begin{array}{l}\text { Sex } \\
\text { male } \\
\text { female }\end{array}$ & $\begin{array}{l}134 \\
190\end{array}$ & $\begin{array}{l}41.36 \\
58.6\end{array}$ \\
\hline $\begin{array}{l}\text { Type of sepsis } \\
\text { EOS } \\
\text { LOS }\end{array}$ & $\begin{array}{l}55 \\
269\end{array}$ & $\begin{array}{l}16.98 \\
83.02\end{array}$ \\
\hline $\begin{array}{l}\text { Diagnosis } \\
\text { confirmed sepsis } \\
\text { clinical sepsis }\end{array}$ & $\begin{array}{l}53 \\
271\end{array}$ & $\begin{array}{l}16.36 \\
83.65\end{array}$ \\
\hline $\begin{array}{l}\text { Outcome } \\
\text { discharged } \\
\text { died } \\
\text { discharged by request }\end{array}$ & $\begin{array}{l}214 \\
80 \\
30\end{array}$ & $\begin{array}{l}66.05 \\
24.69 \\
9.26\end{array}$ \\
\hline
\end{tabular}

EOS - early onset sepsis; LOS - late onset sepsis.

About 50\% (165/324) of the patients received antibiotics without any culture being performed. Only 49.1\% (159/324) of the samples from the patients were cultured. The most common pathogen isolated was Klebsiella pneumoniae (15 out of 159 samples, $9.43 \%$ ). Approximately $62 \%$ of the blood cultures performed showed no growth of any bacteria (Table 2).

The most commonly used antibiotic in the NICU was gentamycin, which was prescribed 234 times, followed by cefotaxime (232) and metronidazole (55) as the second and third most used antibiotics, respectively. A total of 14 different antibiotics were used in the NICU in 2018 (Table 3).

\begin{tabular}{|c|c|}
\hline Pathogen & $\begin{array}{l}\text { Number of samples, } \\
n(\%)\end{array}$ \\
\hline No growth & $99(62.26)$ \\
\hline Klebsiella pneumonia & $15(9.43)$ \\
\hline Escherichia coli & $9(5.66)$ \\
\hline Salmonella sp. & $9(5.66)$ \\
\hline Acinetobacter baumanii & $8(5.03)$ \\
\hline Staphylococcus aureus & $4(2.52)$ \\
\hline Other & $15(9.43)$ \\
\hline
\end{tabular}

\begin{tabular}{|l|l|}
\hline \multicolumn{2}{|l|}{ Table 3. Top five most common antibiotics prescribed } \\
\hline Antibiotics & $\begin{array}{l}\text { Number of prescrip- } \\
\text { tions, } \boldsymbol{n}(\%)\end{array}$ \\
\hline Cefotaxime & $232(71.60)$ \\
\hline Gentamycin & $234(72.22)$ \\
\hline Metronidazole & $55(16.98)$ \\
\hline Amikacin & $50(15.43)$ \\
\hline Meropenem & $39(12.04)$ \\
\hline Other & $52(16.07)$ \\
\hline
\end{tabular}

Overall, 324 medical records containing 662 antibiotic prescriptions were reviewed. Among the different kinds of antibiotics, ampicillin (62.5\%) and cefotaxime $(82.81 \%)$ were used inappropriately used most frequently, while fosfomycin (100\%) was used appropriately (Table 4).

Table 4. Appropriate use of antibiotics based on the Gyssens
flowchart
\begin{tabular}{|l|l|l|}
\hline Antibiotics & $\begin{array}{l}\text { Appropriate } \\
\text { use, } n(\%)\end{array}$ & $\begin{array}{l}\text { Inappropriate } \\
\text { use, } n(\%)\end{array}$ \\
\hline Cefotaxime $(n=232)$ & $41(17.67)$ & $191(82.81)$ \\
\hline Gentamycin $(n=234)$ & $104(44.44)$ & $130(55.56)$ \\
\hline Amikacin $(n=50)$ & $31(62)$ & $19(38)$ \\
\hline Meropenem $(n=39)$ & $23(58.97)$ & $16(41.03)$ \\
\hline Metronidazole $(n=55)$ & $39(70.91)$ & $16(29.09)$ \\
\hline Ampicillin $(n=8)$ & $3(37.50)$ & $5(62.50)$ \\
\hline Ampicillin-sulbactam $(n=30)$ & $18(60)$ & $12(40)$ \\
\hline Cefoperazone-sulbactam $(n=2)$ & $2(100)$ & $0(0)$ \\
\hline Clindamycin $(n=3)$ & $2(66.67)$ & $1(33.33)$ \\
\hline Cefazolin $(n=3)$ & $0(0)$ & $3(100)$ \\
\hline Ceftazidime $(n=3)$ & $2(66.67)$ & $1(33.33)$ \\
\hline Vancomycin $(n=2)$ & $1(50)$ & $1(50)$ \\
\hline Fosfomycin $(n=1)$ & $1(100)$ & $0(0)$ \\
\hline Total & 102 & 560 \\
\hline
\end{tabular}

Table 5. Reasons for inappropriate use of antibiotics

\begin{tabular}{|l|l|l|}
\hline Reason for inappropriate use & $\begin{array}{l}\text { Number of } \\
\text { prescriptions } \\
(n=662)\end{array}$ & $\begin{array}{l}\text { Percentage } \\
\text { (\%) }\end{array}$ \\
\hline Improper choice of antibiotic & 183 & 27.63 \\
\hline Inadequate duration & 107 & 16.16 \\
\hline No antibiotic indication & 100 & 15.11 \\
\hline Improper dosage interval & 3 & 0.45 \\
\hline $\begin{array}{l}\text { Cannot be evaluated (data } \\
\text { incomplete) }\end{array}$ & 2 & 0.30 \\
\hline Appropriate use of antibiotics & 267 & 40.33 \\
\hline
\end{tabular}


Antibiotic therapy was found to be inappropriately used in $59.67 \%$ of the prescriptions. The most common reason for inappropriate use was that more effective antibiotics could have been chosen $(27.63 \%)$. The second most common reason was ineffective/inadequate duration of antibiotic administration against the suspected infection (16.6\%). Approximately $15 \%$ of the antibiotics used were without indication (Table 5).

\section{Discussion}

This study was conducted to evaluate antibiotic prescriptions in the NICU of Adam Malik General Hospital. Complete documentation of clinical features, neonatal sepsis risk factors, laboratory examinations, and management were retrieved from the medical records of all neonatal sepsis patients in 2018 that met the inclusion and exclusion criteria. In our study, we found that more females (58.6\%) were admitted to the NICU than males. This finding was different from a study performed by Tank et al. in Kenya and Pokhrel et al. in Nepal $[13,14]$. Pokhrel et al. found that early-onset sepsis patients were admitted more frequently to the NICU than late-onset sepsis patients; however, in our study, we found that more neonates with late-onset sepsis were admitted to our NICU [13]. This may be explained by our hospital being a tertiary hospital that receives referral cases from other hospitals. Sepsis was confirmed in only $16.36 \%$ of all cultures included in our study. This rate was higher than the one found by Tank et al., who reported only $4 \%$ culture positivity, but it was similar to that reported by Prusakov et al., citing $20 \%$ confirmed sepsis cases in their study $[2,14]$. Low culture positivity is a common problem in pediatric patients, particularly in neonates. The difficulty of the procedure for blood sampling, especially obtaining the optimal volume, is a subject of controversy due to several obstacles, such as low intravascular volume and the risk of causing anemia [15].

Klebsiella pneumoniae was the most common pathogen that we found (4.63\%). This finding was similar to the study conducted by Almohammady et al. in Cairo, who reported an incidence rate of $45.3 \%$ for $K$. pneumoniae among all isolates [16]. However, a study by Yadav et al. found that Staphylococcus aureus was the most common isolate among neonatal sepsis patients in Nepal [17]. Approximately $30 \%$ of our patients did not show any microbial growth. This finding was higher than the rate found in studies by Yadav et al. and Weldu et al. [17, 18].

Antibiotics are the most common drugs prescribed for neonates in the NICU [19]. Given the high mortality associated with neonatal sepsis and the presence of maternal and neonatal risk factors, empirical antibiotics are frequently administered to neonates in the NICU [20]. Gentamycin was the most common antibiotic prescribed in our NICU (72.22\%), followed by cefotaxime (71.60\%). This finding was similar to the results of studies conducted by Prusakov et al. [2]. A combination of meropenem and amikacin was the recommended antibiotic therapy in a study by
Weldu et al., while in our study the most commonly selected combination antibiotic in the NICU was cefotaxime and gentamycin [18]. The different choices of empiric antibiotics were based on the pathogen distributions in particular hospitals.

Antibiotic resistance is a serious global health problem caused by overusing antibiotics. Microbial resistance to antibiotics has increased rapidly over the last few decades with the emergence of super-resistant microbial strains that commonly do not respond to general antibiotics [21]. The overuse of antibiotics is also found in the NICU, where neonates are frequently exposed to antibiotics prescribed for a suspected or proven infection [22]. Cefotaxime was one of the most commonly used antibiotics in our NICU. Surprisingly, we discovered that $82.81 \%$ of the pathogens found in the cultures were resistant to cefotaxime, followed by $55.56 \%$ which were resistant to gentamycin. Therefore, we concluded that the choice of antibiotics for treating neonatal sepsis in our NICU was inappropriate. Our finding was in line with the results of sensitivity tests of antibiotics performed by Pokhrel et al., but was different from the results of a study by Yadav et al. $[13,17]$

In our study, only $40.33 \%$ of antibiotic prescriptions were appropriately prescribed based on qualitative analysis, according to the Gyssens flowchart. This finding was lower than that of a study conducted by Tank et al. [14]. Approximately $59.67 \%$ of antibiotics prescribed in our NICU were inappropriately used for various reasons. One hundred neonates $(15.11 \%)$ received antibiotics even though there was no information on the clinical manifestation, risk factors, or any laboratory results supporting the presence of infection. Our finding was similar to a multicentre study by Hashmi et al. [23]. One hundred seven neonates $(16.16 \%)$ in our study were prescribed an inadequate duration of antibiotic treatment. Despite the improvement of the clinical manifestation of sepsis in neonates, a prolonged use of antibiotics was observed. A similar observation was also reported by Al-Turkait et al. [24]. Because neonatal sepsis could negatively impact mortality, many physicians are sometimes hesitant to discontinue antibiotic administration despite improvement in infection symptoms or clinical appearance [24, 25].

\section{Conclusions}

In conclusion, neonatal sepsis is a life-threatening condition, and antibiotics are essential for clearing infections. However, antibiotic administration is not without risk. The inadequate use of antimicrobial agents will contribute to an increase in neonatal drug-resistant bacterial infections in the NICU, which will lead to high mortality. A comprehensive approach consisting of a rational use of empirical therapy and the discontinuation of therapy when appropriate, the evaluation of antibiotic consumption, and an antimicrobial stewardship program in the NICU are needed to prevent the emergence of drug resistance in the NICU.

Source of funding: This study was supported by RISTEKDIKTI grant scheme DRPM 2019 3/UN5.2.3.1/PPM/KP-DRPM/2019. Conflicts of interest: The authors declare no conflicts of interest.

\section{References}

1. Fleischmann C, Reichert F, Cassini A, et al. Global incidence and mortality of neonatal sepsis: a systematic review and meta-analysis. Arch Dis Child 2021, doi: 10.1136/archdischild-2020-320217.

2. Prusakov P, Goff DA, Wozniak PS, et al. A global point prevalence survey of antimicrobial use in neonatal intensive care units: the nomore-antibiotics and resistance (NO-MAS-R) study. EClinicalMedicine 2021; 32: 100727, doi: 10.1016/j.eclinm.2021.100727.

3. Arora V, Strunk D, Furqan SH, et al. Optimizing antibiotic use for early onset sepsis: a tertiary NICU experience. J Neonatal Perinatal Med 2019; 12(3): 301-312.

4. Rajar P, Saugstad OD, Berild D, et al. Antibiotic stewardship in premature infants: a systematic review. Neonatology 2020; 117(6): 673-686.

5. Rueda MS, Calderon-Anyosa R, Gonzales J, et al. Antibiotic overuse in premature low birth weight infants in a developing country. Pediatr Infect Dis J 2019; 38(3): 302-307. 
6. Villanueva P, Freyne B, Hickey L, et al. Impact of an antimicrobial stewardship intervention in neonatal intensive care: recommendations and implementation. J Paediatr Child Health 2021, doi: 10.1111/jpc.15427.

7. Hauge C, Stålsby Lundborg C, Mandaliya J, et al. Up to $89 \%$ of neonates received antibiotics in cross-sectional Indian study including those with no infections and unclear diagnoses. Acta Paediatr 2017; 106(10): 1674-1683.

8. $\mathrm{Xu} \mathrm{JJ}, \mathrm{Gao} \mathrm{J}, \mathrm{Guo} \mathrm{JH}$, et al. Analysis of antibiotic treatment of children in a Shanghai tertiary hospital based on point prevalence surveys. BMC Infect Dis 2020; 20(1): 804.

9. Wang HC, Liao CC, Chu SM, et al. Impacts of multidrug-resistant pathogens and inappropriate initial antibiotic therapy on the outcomes of neonates with ventilator-associated pneumonia. Antibiotics (Basel) 2020; 9(11): 760.

10. Gkentzi D, Dimitriou G. Antimicrobial stewardship in the neonatal intensive care unit: an update. Curr Pediatr Rev 2019; 15(1): 47-52.

11. Gyssens IC, Broek PJ van den, Kullberg BJ, et al. Optimizing antimicrobial therapy. A method for antimicrobial drug use evaluation. $J$ Antimicrob Chemother 1992; 30(5): 724-727.

12. Meer JW van der, Gyssens IC. Quality of antimicrobial drug prescription in hospital. Clin Microbiol Infect 2001; 7(Suppl. 6): 12-15.

13. Pokhrel B, Koirala T, Shah G, et al. Bacteriological profile and antibiotic susceptibility of neonatal sepsis in neonatal intensive care unit of a tertiary hospital in Nepal. BMC Pediatr 2018; 18(1): 208.

14. Tank PJ, Omar A, Musoke R. Audit of antibiotic prescribing practices for neonatal sepsis and measurement of outcome in New Born Unit at Kenyatta National Hospital. Int J Pediatr 2019; 2019: 7930238, doi: 10.1155/2019/7930238.

15. Huber S, Hetzer B, Crazzolara R, et al. The correct blood volume for paediatric blood cultures: a conundrum? Clin Microbiol Infect 2020; 26(2): 168-173.

16. Almohammady MN, Eltahlawy EM, Reda NM. Pattern of bacterial profile and antibiotic susceptibility among neonatal sepsis cases at Cairo University Children Hospital. J Taibah Univ Med Sci 2020; 15(1): 39-47.

17. Yadav NS, Sharma S, Chaudhary DK, et al. Bacteriological profile of neonatal sepsis and antibiotic susceptibility pattern of isolates admitted at Kanti Children's Hospital, Kathmandu, Nepal. BMC Res Notes 2018; 11(1): 301.

18. Weldu Y, Naizgi M, Hadgu A, et al. Neonatal septicemia at intensive care unit, Ayder Comprehensive Specialized Hospital, Tigray, North Ethiopia: bacteriological profile, drug susceptibility pattern, and associated factors. PLOS ONE 2020; 15(6): e0235391.

19. Bedir Demirdağ $\mathrm{T}, \mathrm{Koç} \mathrm{E}$, Tezer $\mathrm{H}$, et al. The prevalence and diagnostic criteria of health-care associated infections in neonatal intensive care units in Turkey: a multicenter point - prevalence study. Pediatr Neonatol 2021; 62(2): 208-217.

20. Greenberg RG, Chowdhury D, Hansen NI, et al. Prolonged duration of early antibiotic therapy in extremely premature infants. Pediatr Res 2019; 85(7): 994-1000.

21. Makri V, Davies G, Cannell S, et al. Managing antibiotics wisely: a quality improvement programme in a tertiary neonatal unit in the UK. BMJ Open Qual 2018; 7(2): e000285.

22. Flannery DD, Puopolo KM. Neonatal antibiotic use: how much is too much? Pediatrics 2018; 142(3): e20181942, doi: 10.1542/ peds.2018-194223.

23. Hashmi MA, Lodhi MA, Toor KM, et al. Emerging antimicrobial resistance in neonatal sepsis. J Coll Physicians Surg Pak 2020; 30(12): 1312-1315.

24. Al-Turkait A, Szatkowski L, Choonara I, et al. Review of drug utilization studies in neonatal units: a global perspective. Int $J$ Environ Res Public Health 2020; 17(16): 5669, doi: 10.3390/ijerph17165669.

25. Araujo da Silva AR, Jaszkowski E, Schober T, et al. Patterns of antimicrobial consumption in neonatal and pediatric intensive care units in Germany and Brazil. Eur J Clin Microbiol Infect Dis 2020; 39(2): 249-255.

Tables: 5

Figures: 0

References: 25

Received: 03.04.2021

Reviewed: 18.04.2021

Accepted: 13.06.2021

Address for correspondence:

Ayodhia Pitaloka Pasaribu, MD, PhD

Department of Child Health

Medical Faculty

Universitas Sumatera Utara

Jalan Dr. Mansur No. 5

Medan

North Sumatera 20155

Indonesia

Tel.: +62 8126024392

E-mail: ayodhia@usu.ac.id 